\title{
Rehydration of katoite as a layered double hydroxide: an in situ study
}

\author{
Antonia A. L. Pacheco ${ }^{1,0, *}$, Thiago R. S. Nobre ${ }^{1}$, Marcel H. Maciel ${ }^{1}$, Celso V. Santilli ${ }^{2}$, Antonio C. Vieira
} Coelho ${ }^{3}$, Sérgio C. Angulo ${ }^{1}$

\footnotetext{
${ }^{1}$ Department of Construction Engineering, Escola Politécnica, University of São Paulo, São Paulo, Brazil

2 Institute of Chemistry, São Paulo State University, Araraquara, Brazil

${ }^{3}$ Department of Metallurgical and Materials Engineering, Escola Politécnica, University of São Paulo, São Paulo, Brazil
}

- Antonia A. L. Pacheco was invited for submission of this letter as an awardee of the RILEM PhD Grant for the 74th RILEM Annual Week, 2020

Received: 04 November 2020 / Accepted: 06 February 2021 / Published online: 16 March 2021

(C) The Author(s) 2021. This article is published with open access and licensed under a Creative Commons Attribution 4.0 International License.

\begin{abstract}
Calcium aluminate layered double hydroxides (Ca-Al LDHs) constitute a considerable part of cementitious waste fines. Although cementitious waste fines have proven to be recyclable by thermal treatment at moderate temperatures $\left(400-700^{\circ} \mathrm{C}\right)$, understanding how each phase rehydrates and contributes to the binding properties of rehydrated cementitious materials is still necessary. In this study, the dehydration and rehydration of katoite are investigated through in situ techniques, and its applicability as an alternative binder or supplementary cementitious material (SCM) is discussed. The research employed X-ray diffraction, isothermal calorimetry, in situ wide-angle X-ray scattering (WAXS), and rotational/oscillatory rheometry. Katoite synthesized by a mechanochemical process (with contamination of calcite) was dehydrated at $400^{\circ} \mathrm{C}$, producing mainly mayenite. During rehydration, calorimetry presents high heat production in the first minutes. WAXS shows prompt recovery of katoite and increasing formation of monocarboaluminate (Ca-AI LDH) after 30 $\mathrm{s}$ of rehydration. The findings confirm the direct association between rapid heat release and phase reformation. Rehydrated pastes present a high yield stress and an increasing storage modulus, indicating rapid binding properties. The consolidation is also correlated with cumulative heat and monocarboaluminate formation. The results indicate the potential of calcined katoite (with presence of calcite) for use as rapid set alternative binder or SCM.
\end{abstract}

Keywords: Alternative binder; Calcium aluminates; Katoite; Layered double hydroxide; Rehydration

\section{Introduction}

Calcium aluminate layered double hydroxides (Ca-Al LDHs), which include sulfo/carbo calcium aluminates in Portland cements (AFm phases), constitute a considerable part of the phases present in cementitious waste materials [1-3]. Cementitious waste fines are recyclable as cement or supplementary cementitious materials (SCMs) when thermally treated [4]. Specifically, the thermal treatment of Ca-Al LDHs at moderate temperatures $\left(400-700^{\circ} \mathrm{C}\right)$ enables the product to reform and incorporate aggressive ions such as chloride, sulfate, or carbonate during their rehydration [5-7]. Other types of calcined LDHs have also been used to accelerate hydration kinetics when reformed and to increase the early strength of cementitious materials $[8,9]$. Therefore, to optimize the binding capacity of recycled cement, understanding how the different phases (such as LDH phases) rehydrate and how those contribute to the microstructure and binding properties of rehydrated cementitious materials is necessary.

Studies on the recycling of calcium aluminate cement (CAC) as an alternative binder are scarce in the literature. The hydration of CAC causes the formation of metastable Ca-Al $\mathrm{LDH}$ phases [10]. Those are later converted to katoite $\mathrm{Ca}_{3} \mathrm{Al}_{2}(\mathrm{OH})_{12} \quad\left(\mathrm{C}_{3} \mathrm{AH}_{6}\right.$ in cement chemistry notation), that we refer in this paper as the endmember of the hydrogrossular mineral series:

$$
\left(\mathrm{Ca}_{3} \mathrm{Al}_{2}\left(\mathrm{SiO}_{4}\right)_{3-x}(\mathrm{OH})_{4 x} ; 0 \leq x \leq 3\right) \text {, in which } x=3 \text {. }
$$

Katoite is the only stable phase in $\mathrm{CaO}-\mathrm{Al}_{2} \mathrm{O}_{3}-\mathrm{H}_{2} \mathrm{O}$ systems [11] and also the main phase found at the end of the life cycle of refractories and $C A C$ wastes. Its thermal decomposition forms mayenite $\left(\mathrm{Ca}_{12} \mathrm{Al}_{14} \mathrm{O}_{32}\right.$ or $\left.\mathrm{C}_{12} \mathrm{~A}_{7}\right)$ [12]. Zhang et al. also reported that mayenite was the main calcium aluminate phase observed after the dehydration of the cement paste, and it governed the setting of the rehydrated paste [13]. Paul and Chang reported the transformation of mayenite to Ca-Al LDH, which adsorbed chloride ions from water, thus acting in a similar manner to that of calcined Ca-Al LDHs [14].

None of the aforementioned studies investigated the obtention of Ca-Al LDHs from dehydration and rehydration of katoite nor explored the binding potential during this

\footnotetext{
* Corresponding author: Antonia A. L. Pacheco, Email: alanapacheco@usp.br
} 
transformation. This route is interesting not only because katoite can be obtained from cement waste, but also because it can be easily produced through mechanochemical synthesis by grinding $\mathrm{Ca}(\mathrm{OH})_{2}$ and $\mathrm{Al}(\mathrm{OH})_{3}$ in a planetary ball mill $[15,16]$. Moreover, the dehydration of katoite requires lower energy consumption than that involved in the thermal decomposition of other Ca-AI LDHs, as more water molecules must be removed from their structure [17].

Therefore, this study investigates the dehydration and rehydration of synthetized katoite (obtained by mechanosynthesis) in water using in situ techniques and discusses its potential applicability as an alternative binder. $X$ ray diffractometry (XRD), isothermal calorimetry, and in situ wide-angle X-ray scattering (WAXS) performed with synchrotron radiation are used to observe the phase transformations. To explore the binding capacity of the material, rotational and oscillatory rheometry are also performed. Through these techniques, the study established correlations between phase consumption and formation with the heat release and consolidation of the rehydrated paste.

\section{Materials and synthesis methods}

\subsection{Materials}

Figure 1 outlines the methodology used in this research. Katoite $\left(\mathrm{C}_{3} \mathrm{AH}_{6}\right)$ was synthesized through a mechanochemical method by milling a $50-\mathrm{g}$ mixture with a $\mathrm{Ca} / \mathrm{Al}$ ratio of $3: 2(\mathrm{~mol} / \mathrm{mol})$ from two reagents. The first reagent had $92 \%$ of $\mathrm{Ca}(\mathrm{OH})_{2}$ and $8 \%$ of $\mathrm{CaCO}_{3}$. The second reagent was composed of pure $\mathrm{Al}(\mathrm{OH})_{3}$ (P.A., Synth). A planetary ball mill (Fritsch, Pulverissette 6 MonoMill) was used with stainless steel balls having diameters of 5 , 10 , and $20 \mathrm{~mm}$. The milling was conducted at room temperature, maintaining a constant speed of $500 \mathrm{rpm}$ for 1 $\mathrm{h}$, pausing every $10 \mathrm{~min}$ to remove the material from the jar wall and to avoid overheating. No water was added in the mixture. The synthesis conditions were similar to those reported by Nobre et al. [15]. This one-step method was chosen due to its simplicity and fast synthesis of katoite, as shown in other works $[15,16,18]$. XRD analysis confirmed the main formation of katoite, but also the presence of calcite (see Figure 2), an impurity from the calcium-based reagent.

The synthesized katoite was calcined at $400{ }^{\circ} \mathrm{C}$ for $2 \mathrm{~h}$ and then cooled at room temperature in a desiccator. These conditions were chosen to decompose the katoite completely. The calcined powder had a mean particle size $\left(D_{50}\right)$ of $12.1 \mu \mathrm{m}$, in which the particle-size distribution had a $D_{10}$ of $1.45 \mu \mathrm{m}$ and $D_{90}$ of $58.3 \mu \mathrm{m}$, determined by a laser diffraction particle-size analyzer (Mastersizer 3000, Malvern Instruments) with isopropyl alcohol as a dispersant. The powder had a density of $2.51 \mathrm{~g} / \mathrm{cm}^{3}$ and a specific surface area of $6.9 \mathrm{~m}^{2} / \mathrm{g}$. These two properties were determined by using an helium pycnometer (MVP 5 DC, Quantachrome Instruments) and by applying the Brunauer-Emmett-Teller method to $77 \mathrm{~K} \mathrm{~N}_{2}$ nitrogen adsorption data (Belsorp Max equipment), respectively.

Finally, the dehydrated katoite powder was rehydrated in deionized water with a minor quantity of carbonate ions $(\mathrm{pH}$ 5.8) at a water/solid ratio (in mass) of 1.2. This quantity of water was required to ensure plastic consistency of the paste, as the calcined powder demanded more water because of its high surface area. The powder was hand-mixed with water for $30 \mathrm{~s}$ and then mixed for $1 \mathrm{~min}$ at $10000 \mathrm{rpm}$ in a Makita RT0700C mixer to form an homogeneous paste. To simulate real application conditions, the rehydration was not conducted under an inert atmosphere. Thus, the presence of carbonate ions in the water due to the impurity from the calcium-based reagent, and $\mathrm{CO}_{2}$ from the atmosphere, should influence the phase assemblage through the easy incorporation of $\mathrm{CO}_{2}$ in LDH structures [19].

\subsection{Characterization techniques}

X-Ray Fluorescence (XRF) analysis was performed in the synthesis and in the rehydrated products on a Panalytical Magix Pro spectrometer using fused bead method (sample:fluxer = 1:7 in Pt:Au crucibles, Spectromelt A10Merck as fluxer) and expressed in main oxides. Loss on ignition (LOI) was determined after $2 \mathrm{~h}$ at 1,020 $\circ$ C.

XRD was used to identify the main phases of the synthesis, and of both the dehydration and rehydration of katoite after $24 \mathrm{~h}$. The XRD powder analysis was performed on a Panalytical X'PERT diffractometer, with CUK $\alpha$ radiation, operating at $40 \mathrm{kV}-40 \mathrm{~mA}$. The analysis was performed at room temperature at a step of $0.02^{\circ} 2 \theta, 4 \mathrm{~s}$ per step. The peaks were indexed using Panalytical X-Pert HighScore Plus software using Crystallography Open Database (COD) files.

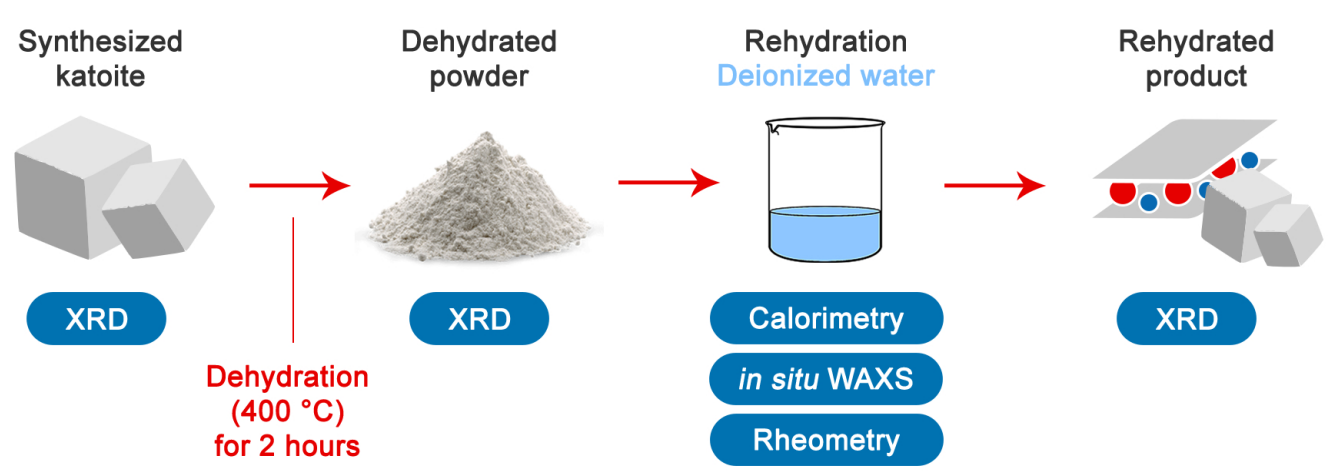

Figure 1. Methodology of the research. 
Table 1. Chemical composition of synthesized and rehydrated products (mass fraction, \%).

\begin{tabular}{|l|l|l|l|l|l|l|l|l|l|l|l|l|l|}
\hline & $\mathrm{CaO}$ & $\mathrm{Al}_{2} \mathrm{O}_{3}$ & $\mathrm{SiO}_{2}$ & $\mathrm{Na} 2 \mathrm{O}$ & $\mathrm{K}_{2} \mathrm{O}$ & $\mathrm{MgO}$ & $\mathrm{Fe}_{2} \mathrm{O}_{3}$ & $\mathrm{P}_{2} \mathrm{O}_{5}$ & $\mathrm{SrO}$ & $\mathrm{TiO}_{2}$ & $\mathrm{SO}_{3}$ & $\mathrm{Cl}$ & $\mathrm{LOI}$ \\
\hline $\begin{array}{l}\text { Synthesize } \\
\text { d product }\end{array}$ & 42.2 & 22.5 & 0.48 & 0.26 & $<0.1$ & 0.25 & 0.07 & 0.03 & 0.02 & 0.02 & 0.14 & 0.02 & 33.9 \\
\hline $\begin{array}{l}\text { Rehydrated } \\
\text { product }\end{array}$ & 38.3 & 20.5 & 0.38 & $0.79 *$ & $<0.1$ & 0.36 & 0.04 & 0.07 & 0.06 & 0.02 & 0.14 & $0.18^{*}$ & 39.3 \\
\hline
\end{tabular}

$(*)$ differences were attributed to sampling error or some contamination of sample.

LOI determined after $2 \mathrm{~h}$ at $1,020 \mathrm{oC}$.
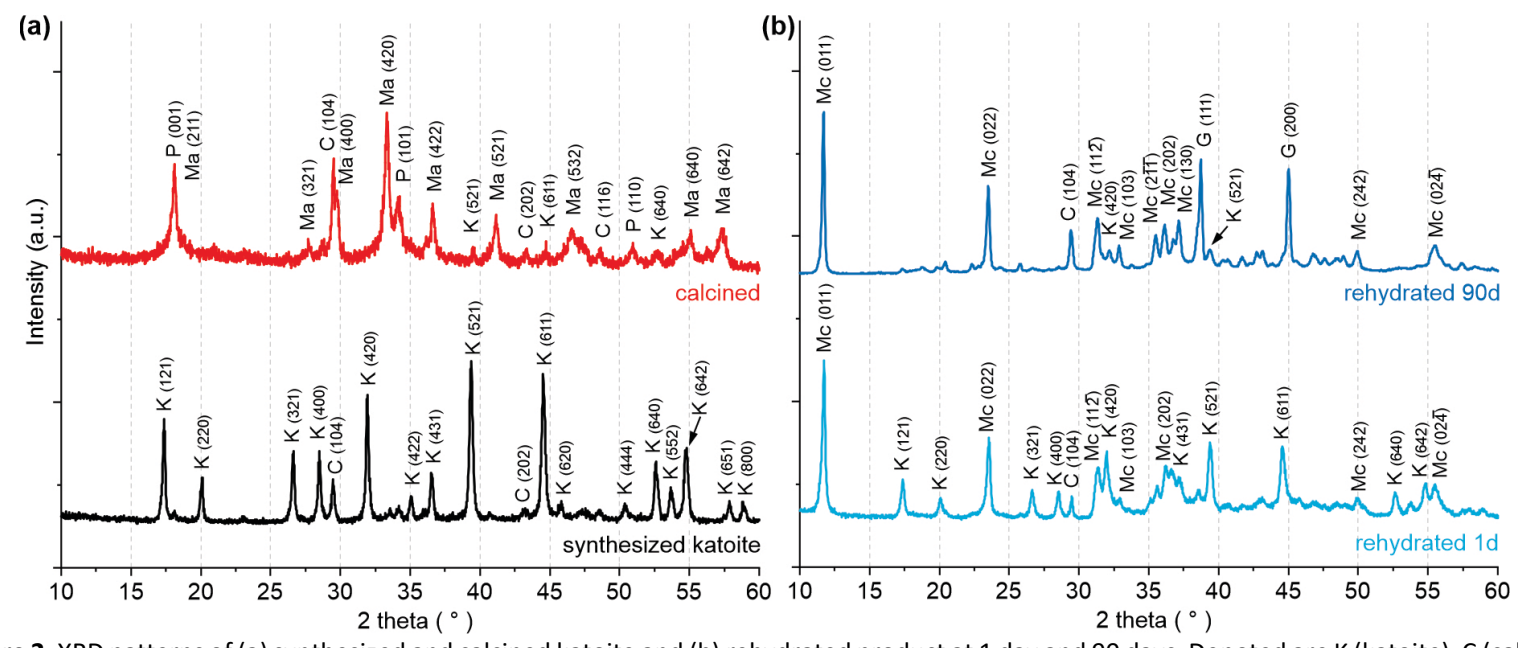

Figure 2. XRD patterns of (a) synthesized and calcined katoite and (b) rehydrated product at 1 day and 90 days. Denoted are $\mathrm{K}$ (katoite), $\mathrm{C}$ (calcite), $\mathrm{P}$ (portlandite), Ma (mayenite), Mc (monocarboaluminate) and G (griceite, internal standard).

Isothermal calorimetry at room temperature was conducted to evaluate the heat release during rehydration using a TAM air calorimeter (TA Instruments). Data were collected for 48 h. The mixing was performed outside the calorimeter following the method described in the previous section. After mixing, the paste was immediately placed in the equipment. The measurement started approximately 4 min after mixing the powder with water.

The phase transformations during the reformation of compounds were followed by in situ WAXS performed with synchrotron radiation. The analysis was conducted at room temperature in the SAXS1 beamline at the Brazilian Synchrotron Light Laboratory (LNLS). The measurements used a monochromatic beam at $\lambda=1,55 \AA$ ( $8 \mathrm{KeV})$ and a bidimensional detector (Pilatus 300k) located $233.8 \mathrm{~mm}$ from the sample. The calcined powder was pressed into a tablet and placed in the sample holder, and then deionized water was added at room temperature. SAXS data registered the scattering intensity $(\mathrm{I})$ as a function of the magnitude of the scattering vector (q). The $d$-spacing of each diffraction peak followed the equation $d=2 \pi / q$.

To investigate the binding potential of katoite during rehydration, parallel-plate rotational rheometry was used to assess the rheological characteristics of the fresh paste during the flow. In addition, oscillatory rheometry was performed to monitor the paste consolidation. The tests were conducted at $25^{\circ} \mathrm{C}$ in a HAAKE MARS rheometer (ThermoFisher Scientific) using stainless steel parallel plates with a diameter of $40 \mathrm{~mm}$. For both tests, the paste as produced was placed immediately between the plates, and the gap distance was set to $1 \mathrm{~mm}$. Excess material was removed. The rotational test consisted of two consecutive shear cycles. In both cycles, the shear rate varied linearly from 0 to $50 \mathrm{~s}^{-1}$ in $1 \mathrm{~min}$ and then returned to $0 \mathrm{~s}^{-1}$ again in $1 \mathrm{~min}$. Only the second cycle data were used in the analysis to reduce paste heterogeneities that may have occurred in the first cycle [20]. The oscillatory test was conducted for $60 \mathrm{~min}$ at a constant frequency of $1 \mathrm{~Hz}$ and strain of $10^{-4}$ to avoid destructive measurements during consolidation. In the oscillatory test, a pre-shear of $5 \mathrm{~s}^{-1}$ for 30 $s$ was performed to eliminate the previous stress of the material. Both rotational and oscillatory tests started $4 \mathrm{~min}$ after the first contact with water. The tests were conducted in two different batches.

\section{Results and discussion \\ 3.1 XRF and XRD analyses}

The initial stoichiometry of the mixture was $\mathrm{Ca} / \mathrm{Al}$ ratio of 3:2 (mol $/ \mathrm{mol}$ ). The $\mathrm{CaO} / \mathrm{Al}_{2} \mathrm{O}_{3}$ ratio (in mass) expected is 1.65 . XRF chemical analyses of synthesized and rehydrated products were presented in Table 1 . The $\mathrm{CaO} / \mathrm{Al}_{2} \mathrm{O}_{3}$ ratios of the products were equal to $1.88, \sim 14 \%$ higher than the initial stoichiometry condition; but the difference in the contents of the oxides, in relative terms, is lower than $8 \%$, acceptable for experiments.

Figure 2(a) shows the XRD patterns of the synthesized and calcined katoite. Mechanosynthesis produced well-formed $\mathrm{C}_{3} \mathrm{AH}_{6}$ (COD 9001772). In addition, calcite (COD 9000966) was identified at a low concentration because of the calciumbased reagent impurity and also some inevitable sample carbonation that may occur. As previously reported $[15,16,18]$, the synthesis method used here is simpler than those used in other studies, where the latter obtained katoite through hydrothermal synthesis $[21,22]$ or the production of tricalcium aluminate $[12,23]$. 
The calcination of katoite produced mainly mayenite $\left(\mathrm{C}_{12} \mathrm{~A}_{7}\right.$ COD 2102957; $\mathrm{CaO} / \mathrm{Al}_{2} \mathrm{O}_{3}$ ratio= 0.9; in mass). Its transformation was also reported in the study of RivasMercury et al. [12]. In accordance with the literature $[12,24,25]$, our study observed the formation of portlandite (COD 1001768) in the dehydration, and it is coherent to keep the $\mathrm{CaO} / \mathrm{Al}_{2} \mathrm{O}_{3}$ equal to 1.8. The XRD pattern of dehydrated product still contained the remaining low-intensity peaks of katoite. Finally, the broadening of the peaks and higher background may have indicated the presence of an amorphous fraction, which could be correlated to the formation of intermediate phases or poorly crystallized mayenite.

The XRD patterns of the rehydrated product after 1 day and 90 days of rehydration are exhibited in Figure 2(b). After 1 day of rehydration, the diffractogram reveals the formation of calcium monocarboaluminate (COD 1000459) and the reformation of katoite. Monocarboaluminate is a Ca-AI LDH that was easily formed in the presence of carbonate ions (from the calcium-based reagent impurity) or in the mixing water due to the dissolution of atmospheric $\mathrm{CO}_{2}$. This formation occurs because carbonate ions show higher affinity and easy intercalation in the LDH structure [19]. Soukal et al. observed the formation of monocarboaluminate in the hydration of calcium aluminates, particularly at a high $\mathrm{pH}$ [26]. Baldusco et al. also reported the formation of carboaluminates in the rehydration of blast-furnace slag cement pastes [2].

The rehydration of calcined katoite occurred as reported previously by Schröpfer and Bartl [25]. However, we did not observe the intermediate phase $\mathrm{C}_{12} \mathrm{~A}_{7} \mathrm{H}_{15}$. Although portlandite is one of the decomposition products of katoite, according to the aforementioned authors, it does not participate in the reformation of $\mathrm{C}_{3} \mathrm{AH}_{6}$. Thus, in our study, portlandite may have contributed to the formation of monocarboaluminate.

After 90 days of rehydration, the relative peak intensities of katoite diminished and the intensities of monocarboaluminate increased. An XRD-Rietveld analysis of this pattern, collected with griceite (COD 1010990) as internal standard, indicated $66 \%$ of monocarboaluminate, $24 \%$ of amorphous content (that could include $\mathrm{AH}_{3}$ and other poorly crystalized calcium aluminates), $2 \%$ of bayerite $\left(\mathrm{AH}_{3}\right)$, $5 \%$ calcite (remaining from the synthesis) and $3 \%$ of katoite. Thus, since monocarboaluminate has a $\mathrm{CaO} / \mathrm{Al}_{2} \mathrm{O}_{3}$ ratio (in mass) of 2.2, the remaining aluminum in the system from amorphous $\mathrm{AH}_{3}$ (probably) and katoite could keep the $\mathrm{CaO} / \mathrm{Al}_{2} \mathrm{O}_{3}$ (in mass) of the system equal to 1.88 .

\subsection{Calorimetry analysis}

Figure 3 displays the heat flow and cumulative heat of the rehydration reaction until $48 \mathrm{~h}$ of monitoring. Heat liberation was higher in the first minutes (Figure $3(a)$ ). The heat flow exhibited only one peak after $3 \mathrm{~min}$ of reaction. Although no other peak showing heat released was observed, the cumulative heat (Figure 3 (b)) continued to increase until 48 h. In addition, it is noteworthy that after $13 \mathrm{~min}$, the cumulative heat was $50 \%$ of the total heat released in $48 \mathrm{~h}$
$(294 \mathrm{~J} / \mathrm{g})$. Because the XRD pattern showed stabilization of the rehydrated phases in $24 \mathrm{~h}$, the heat peak may have been associated with the rapid reformation of the phases.
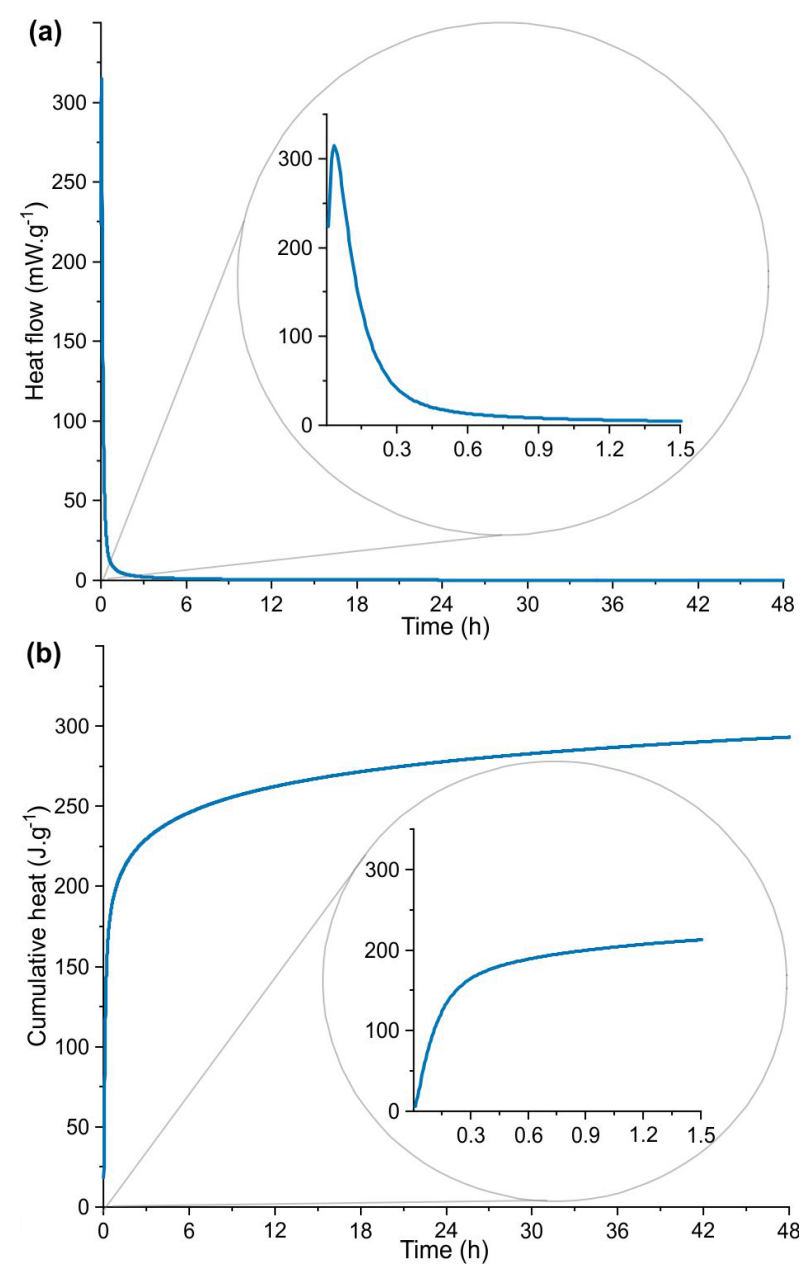

Figure 3. Heat flow (a) and cumulative heat (b) during 48-h of rehydration.

These results agreed with those from previous studies. Mayenite reacted very rapidly with water, achieving more than $60 \%$ of the hydration degree in $30 \mathrm{~min}[27,28]$. However, the reaction in this study did not present a second peak of heat released as in the work of Soukal et al. [26], which indicated the formation of metastable calcium aluminate hydrates after $4 \mathrm{~h}$. The rapid reaction was more comparable to the work of Paul and Chang [14], which showed rapid conversion of mayenite to LDH through hydration in a solution with chloride ions, where an initial fast adsorption stage (within 20 min of reaction) was observed. None of these works obtained mayenite from the calcination of hydrated phases.

\subsection{In situ WAXS}

Figure 4 shows the monitoring of rehydration of calcined calcium aluminate by in situ WAXS. The patterns indicated the prompt recovery of the katoite phase and the formation of monocarboaluminate within $30 \mathrm{~s}$ of rehydration. Hydration evolution revealed the consumption of mayenite with time, 
but a low-intensity peak was still present at $90 \mathrm{~min}$. Simultaneously, the intensity of the monocarboaluminate peaks increased as the hydration time progressed, indicating a continuous development of the phase.

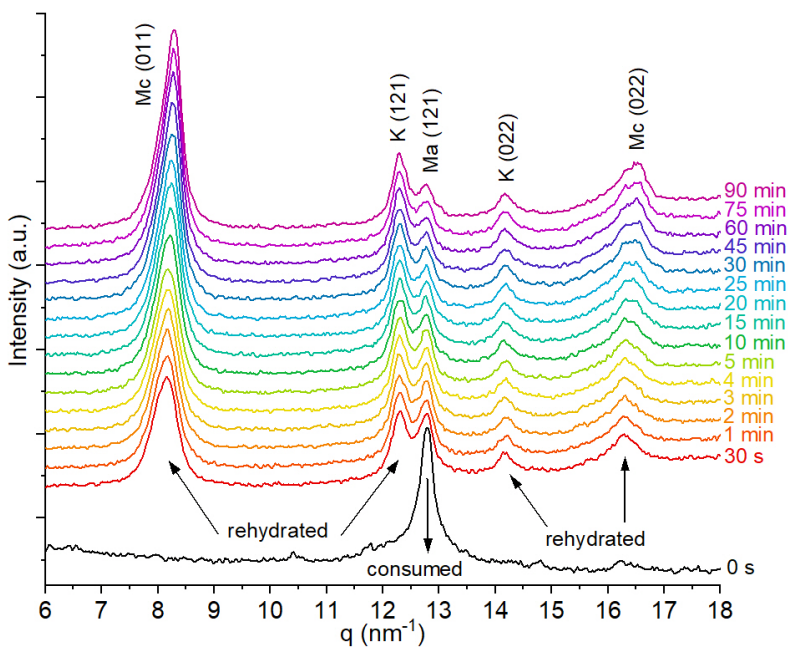

Figure 4. WAXS patterns of the rehydration of calcined calcium aluminate at room temperature. Denoted are Mc (monocarboaluminate), K (katoite), and Ma (mayenite).

The formation of monocarboaluminate over time was determined by the integrated peak area (011), which indicated a fast rate of formation in the first minutes (Figure 5 (a)). The cumulative heat plotted for comparison also followed a similar exponential trend. The heat released during the rapid rehydration seemed to be directly associated with the formation of Ca-AI LDH. Similarly, Figure 5 (b) shows a high mayenite consumption rate in the first $30 \mathrm{~min}$. The correlation of the peak areas (Figure 6) also revealed a linear relationship between the formation of $\mathrm{Ca}-\mathrm{Al} \mathrm{LDH}$ and the consumption of mayenite.

Otherwise, the formation of katoite over time (Figure 5 (b)) exhibited two stages. Until approximately $30 \mathrm{~min}$, the first stage showed that the amount of phase reformed remained nearly invariant. In the second stage, the katoite peak area decreased linearly, indicating phase consumption. The crossover point between the stages coincided with the mayenite slower rate of consumption. Thus, katoite may have also contributed to the formation of Ca-Al LDH following the greater consumption of mayenite.

In the absence of $\mathrm{CO}_{2}$, other $\mathrm{Ca}-\mathrm{Al} \mathrm{LDHs}$ with $\mathrm{OH}^{-}$in the interlayer such as $\mathrm{CAH}_{10}, \mathrm{C}_{2} \mathrm{AH}_{8}$ and $\mathrm{C}_{4} \mathrm{AH}_{13}$, would have formed in the rehydration, but those are metastable in relation to katoite at room temperature [11]. The formation of monocarboaluminate over time occurred due to the availability of $\mathrm{CO}_{3}^{2-}$ from calcium-based reagent impurity and from the mixing water (with traces of carbonate ions from dissolved atmospheric $\mathrm{CO}_{2}$ ), becoming a more stable phase than katoite [29].

Figure 7 shows the time evolution of the crystallite sizes of the phases.

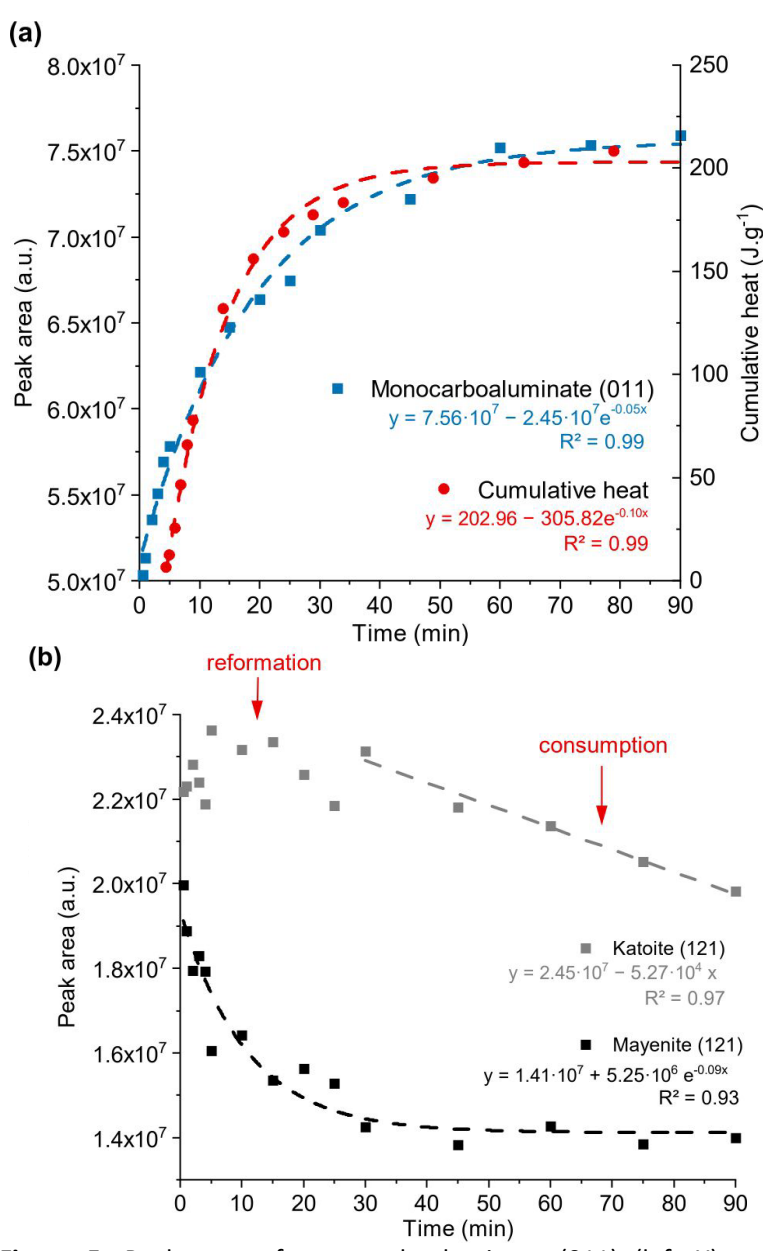

Figure 5. Peak area of monocarboaluminate (011) (left $Y$ ) and cumulative heat (right $Y$ ) versus time (a), and peak areas of katoite (121) and mayenite (121) versus time (b). Please note the differences in scale.

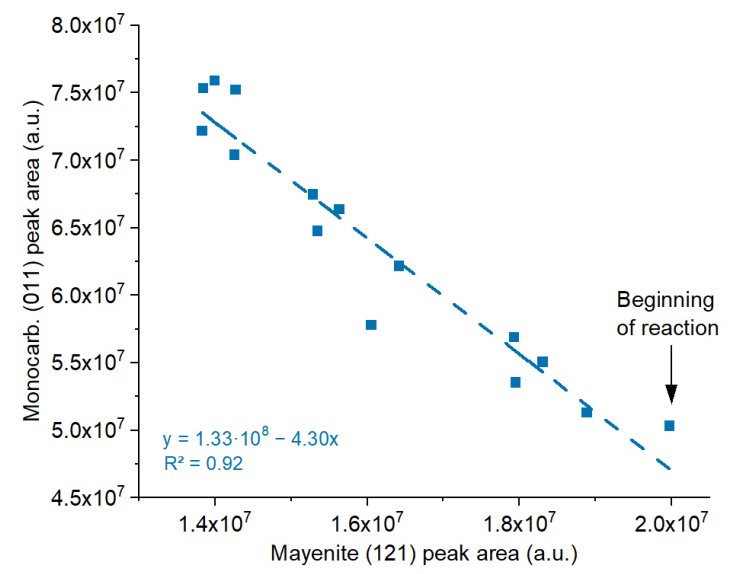

Figure 6. Monocarboaluminate (011) versus mayenite (121) peak areas.

The average crystallite sizes (D) of monocarboaluminate (011), katoite (121), and mayenite (121) were calculated using the Scherrer equation, $D=0.9 \lambda / \beta \cos \theta$, where $\lambda$ is the $X$-ray wavelength, $\beta$ is the peak width at half-maximum, and $\theta$ is the Bragg diffraction angle. The peak deconvolution used a Lorentz function, and the peak width was assumed to be simply due to size effects [30]. 
Two stages were observed in the evolution of the Ca-Al LDH crystallite size. First, it remained quite constant until $10 \mathrm{~min}$ of reaction. It then increased linearly with the cube root of time. The first steady state may correspond to the nucleation of Ca-Al LDH, in which the phase quantity increases but the particle size continues to be approximately the same. The linear second stage may indicate particle growth following the Ostwald ripening mechanism, in which the small crystals dissolve and re-deposit on the surfaces of larger crystals $[31,32]$. Note that mayenite crystallite size decreased. The katoite crystallite size also increased after 10 min, suggesting that the small particles dissolved to form Ca-Al LDH.

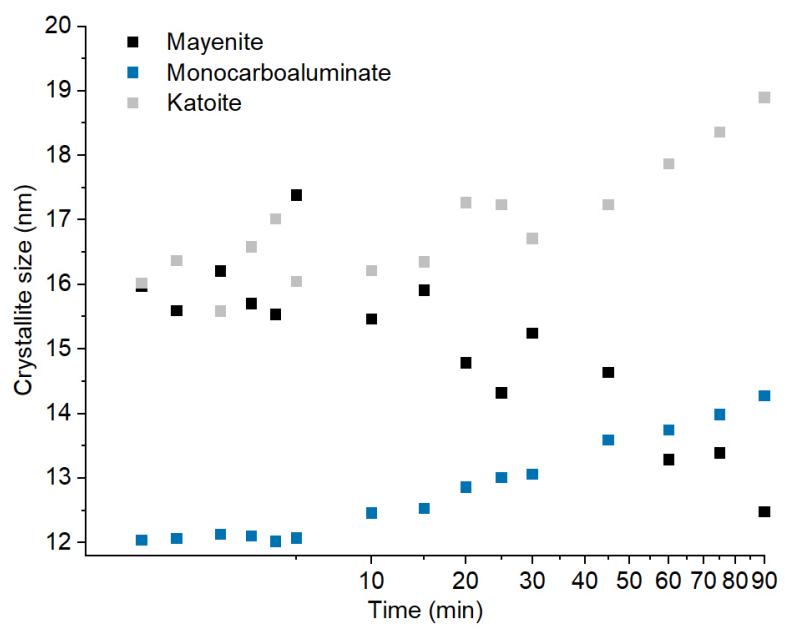

Figure 7. Average crystallite size of monocarboaluminate, katoite, and mayenite as a function of time in cubic root scale.

\subsection{Rheometry}

Rheological curves from rotational rheometry of the rehydrated paste are shown in Figure 8. The first points of the acceleration curve presented higher levels of shear stress due to previous stress that arose when the sample was placed in the equipment. The suspension presented a Bingham-like behavior, in which the shear stress and the shear rate exhibited a linear relationship (Figure 8 (a)). The apparent yield stress and apparent viscosity were determined at the minimum and maximum points of the shear rate, respectively. The values observed were $68.8 \mathrm{~Pa}$ and $1.71 \mathrm{~Pa} . \mathrm{S}$, respectively. The yield stress and viscosity were also calculated using the Bingham model $\left(\tau=\tau_{0}+\mu \gamma\right)$, resulting in 68.6 Pa and 0.35 Pa.s, respectively. In addition, the material exhibited a thixotropic behavior with a slight hysteresis area of 121.17 Pa.s ${ }^{-1}$.

In cement, a minimum applied stress (yield stress) is typically required to initiate flow, and this corresponds to the energy required to break the interaction between particles, which leads to agglomeration [33]. Moreover, even with a water/solid ratio of 1.2 in mass (solid volume fraction of $32 \%$ ), the paste presented a considerably high yield stress. This value is comparable to both Portland cement suspension paste with a high volume fraction of solids such as 55\% [34] and the apparent yield stress of CAC pastes produced with a water/cement ratio of 0.35 [35]. The calculated Bingham viscosity presented similar values of recycled cement pastes with a water/cement ratio of 0.55 [36]. Therefore, the rehydrated paste presented a yield stress and apparent viscosity many times greater to those of the conventional or recycled Portland cement pastes with respect to the water/solid relationship.
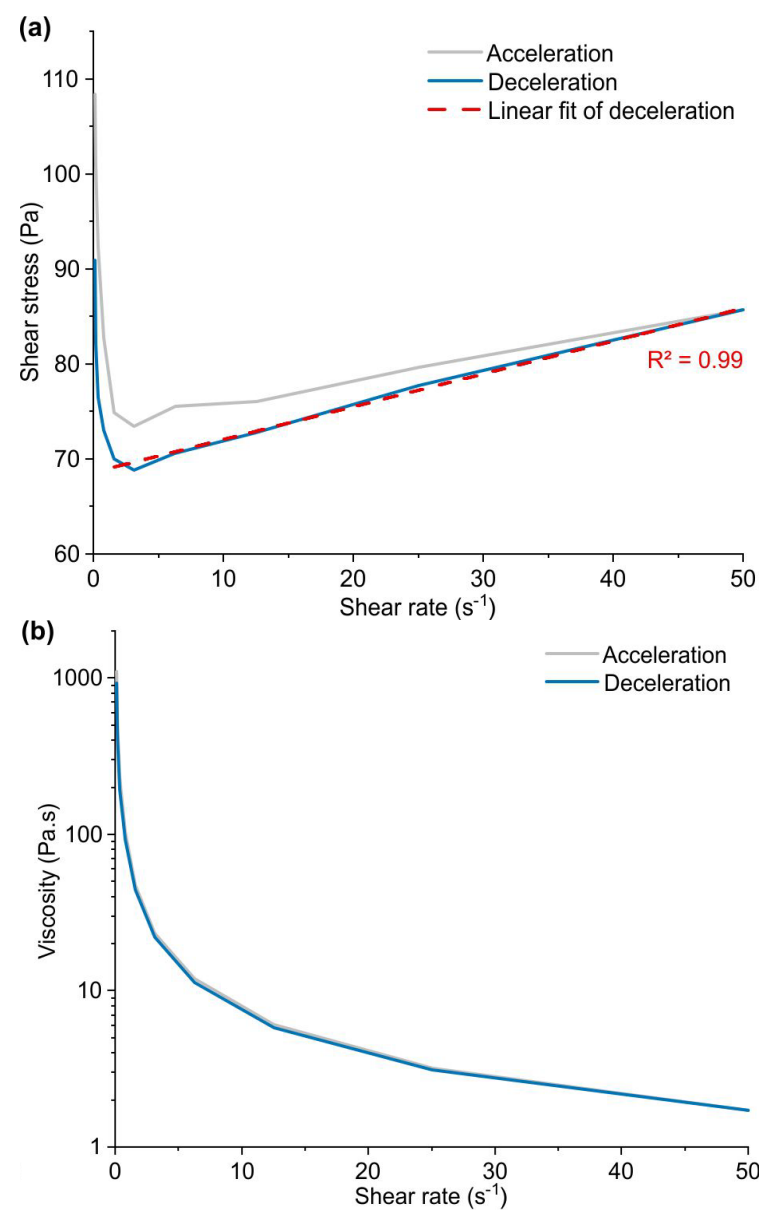

Figure 8. Shear stress (a) and viscosity (b) of the rehydrated paste as a function of shear rate.

Tests conducted with oscillatory rheometry exhibited the elastic storage modulus $\left(G^{\prime}\right)$ of the rehydrated paste as a function of time (Figure 9). The storage modulus is associated with the linear viscoelastic properties of the paste, and its evolution is directly correlated with the paste stiffening $[20,37]$. More details about oscillatory rheometry can be found in [38]. The $G^{\prime}$ value of the rehydrated paste increased with time, showing that the paste consolidated during the first $60 \mathrm{~min}$ of rehydration. The storage modulus reached 3.14 $\times 10^{7} \mathrm{~Pa}$ in $60 \mathrm{~min}$, a value more than 10 times higher than that of conventional cement pastes [39]. These findings indicate the rapid binding capacity of calcined katoite. 


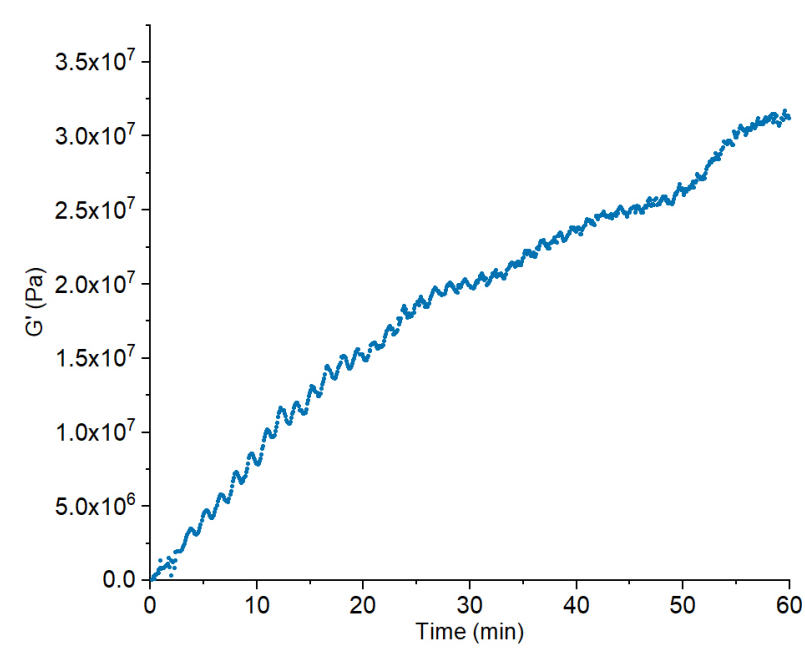

Figure 9. Storage modulus $\left(\mathrm{G}^{\prime}\right)$ of the rehydrated paste as a function of time.

To associate the phase transformation with its physical properties, the obtained values of $\mathrm{G}^{\prime}$ were plotted against the cumulative heat and monocarboaluminate WAXS intensities presented previously. Figure 10 (a) shows that $G^{\prime}$ and cumulative heat were correlated by an exponential function at up to $60 \mathrm{~min}$ of reaction. A similar trend was also observed between the $\mathrm{G}^{\prime}$ and monocarboaluminate diffraction peak intensities (Figure 10 (b)). Thus, the analysis confirmed the correlation between the heat released in the rehydration reaction, the formation of crystalline monocarboaluminate (Ca-AI LDH), and paste consolidation.

The exponential relation showed that the kinetics of consolidation was more accelerated than the formation of hydrates. Fourmentin et al. indicated that the consolidation of cementitious suspensions begins by the attachment of hydrates at the contact points between particles, and the strengthening of the structure is enhanced by pore filling after hydrate formation during the acceleration period [40]. As the rehydrated paste has a kinetics reaction faster than that of ordinary Portland cement pastes, this effect was more evident in this type of material.

Calcined katoite rehydrated and consolidated like a binding material, as shown by rheological results. On one side, the fast consolidation can be useful in 3D printing technology [42]. On the other side, the high specific surface area of calcined katoite, and the high yield stress of the paste can limit its use alone. Exploratory flexural strength tests were also done in the rehydrated pastes, with water/solid ratio of 0.5 (in mass). Since the consistency of the paste was dry, those were mold as board-shape specimens $(60 \times 20 \times 7 \mathrm{~mm})$, pressed with 4 $\mathrm{kPa}$. The average flexural strength was $2.5 \mathrm{MPa}$, appropriate for civil construction applications. Therefore, calcined katoite in the presence of carbonate ion has potential to be used as hardening alternative binder or as an SCM, as already explored for other calcined Ca-Al LDHs $[8,9,41]$.

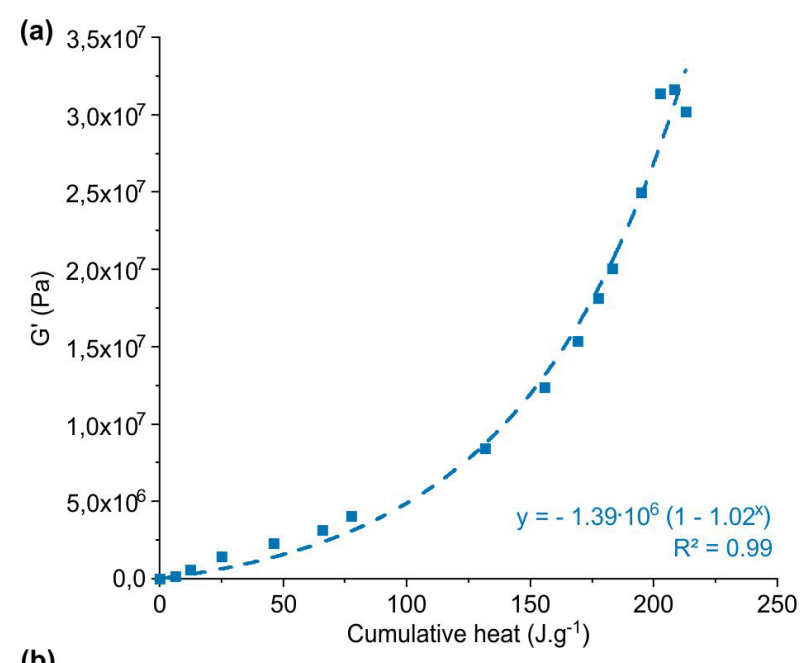

(b)

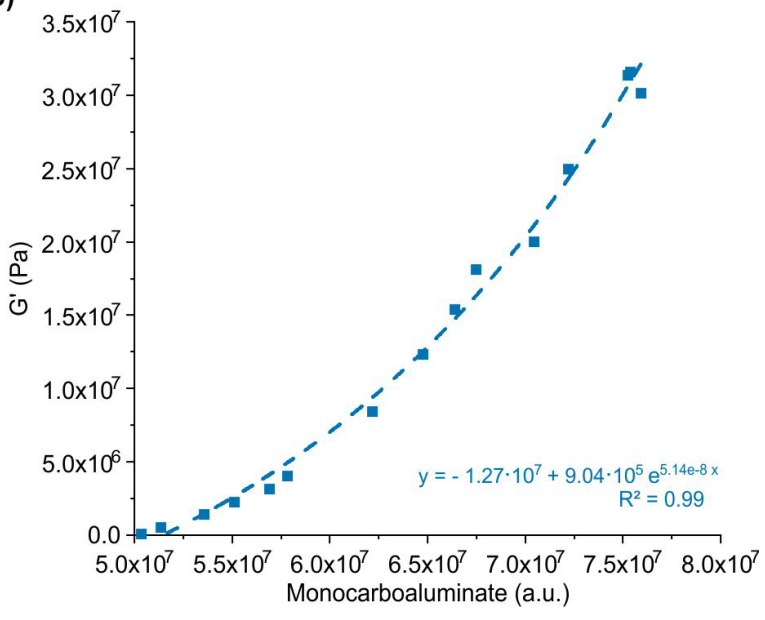

Figure 10. $\mathrm{G}^{\prime}$ as a function of cumulative heat (a) and monocarboaluminate WAXS intensity (b).

Moreover, the calcined katoite can be easily produced by mechanosynthesis and dehydration at low temperatures, and possibly to be obtained by recycling end-life CAC products. In the presence of carbonate ions, the formation of monocarboaluminate is favored and it contributes to the adsorption of $\mathrm{CO}_{2}$ in the solution. An exploratory experiment has shown that $\mathrm{pH}$ of the solution did not change during rehydration, remaining near 13 over time. However, the carbonate ion adsorption in the binder and its contribution to the durability of steel-reinforced cementitious binder system can be limited and needs to be investigated over time, since $\mathrm{CO}_{2}$ adsorption occurs principally in the first days.

\section{Conclusion}

This research investigated the rehydration of an hydrated calcium aluminate phase (katoite) using in situ techniques. Katoite was obtained by mechanosynthesis and was dehydrated at $400{ }^{\circ} \mathrm{C}$, forming mayenite, portlandite, and possibly amorphous phases. Calcined katoite rehydrated in water produced a high amount of heat released during the first minutes, with a single peak at 3 min of reaction. In situ WAXS revealed the prompt recovery of katoite, consumption of mayenite, and increased formation of 
monocarboaluminate (Ca-Al LDH) after $30 \mathrm{~s}$ of contact with water. The formation of monocarboaluminate occurred due to the presence of $\mathrm{CO}_{3}{ }^{2-}$ ions from calcium-based reagent impurity and from the mixing water with dissolved atmospheric $\mathrm{CO}_{2}$. The findings confirmed that the heat released during rapid rehydration was directly associated with Ca-Al LDH formation. In addition, katoite may have also contributed to the formation of monocarboaluminate. The Ca-Al LDH formation followed a first nucleation stage until 10 min of reaction and then a particle growth stage consistent with the Ostwald ripening mechanism.

Rheological analysis of the paste revealed Bingham-like behavior with a yield stress comparable to that of Portland cement paste suspensions with a high-volume fraction of solids. The increase in the storage modulus of the pastes indicated the rapid binding capacity of the material. Further analysis established an exponential correlation between the paste consolidation and the heat released as well as between paste consolidation and crystalline Ca-Al LDH formation (monocarboaluminate). Thus, katoite can rehydrate to form Ca-Al LDHs. The fast consolidation and flexural strength show potential for using the material as a rapid hardening alternative binder or as an SCM.

\section{Acknowledgments}

This study was supported by LNLS (proposal 20180244), CNPq (process 423072/2018-8/Universal), and FAPESP (process 2014/50948-3, INCT CEMtec). The authors thank the Institute for Technological Research (IPT) for the use of laboratory facilities. Antonia A. L. Pacheco acknowledges CNPq grant number 140054/2020-0, and Sérgio C. Angulo acknowledges CNPq grant number 305564/2018-8. Antonio C. Vieira Coelho acknowledges FAPESP grant number 2019/27284-5. The authors also thank the reviewers whose comments helped to improve this manuscript.

The views presented in this study are those of the authors and do not necessarily reflect the opinions of either CNPq or FAPESP.

\section{CRediT authorship statement}

A.A.L. Pacheco: Writing - original draft, Formal analysis, Investigation, Visualization.

T.R.S. Nobre: Writing - review and editing, Methodology, Formal analysis, Investigation.

M.H. Maciel: Writing - review and editing, Investigation.

C.V. Santilli: Conceptualization, Writing - review and editing, Methodology, Supervision.

A.C.Vieira Coelho: Conceptualization, Writing - review and editing, Resources, Supervision, Funding acquisition.

S.C. Angulo: Conceptualization, Writing - review and editing, Methodology, Resources, Supervision, Funding acquisition, Project administration.

\section{References}

[1] J.A. Bogas, A. Carriço, A.J. Tenza-Abril, Microstructure of thermoactivated recycled cement pastes. Cem Concr Res (2020) 138: 106226. https://doi.org/10.1016/j.cemconres.2020.106226

[2] R. Baldusco, T.R.S. Nobre, S.C. Angulo, V.A. Quarcioni, M.A. Cincotto. Dehydration and rehydration of blast furnace slag cement. J Mater Civil Eng (2019) 31(8): 04019132. https://doi.org/10.1061/(ASCE)MT.1943-5533.0002725

[3] M. Vyšvařil, P. Bayer, M. Chromá, P. Rovnaníková. Physicomechanical and microstructural properties of rehydrated blended cement pastes. Constr Build Mater (2014) 54: 413-420. https://doi.org/10.1016/j.conbuildmat.2013.12.021

[4] A. Carriço, J.A. Bogas, M. Guedes, Thermoactivated cementitious materials - A review. Constr Build Mater (2020) 250: 118873. https://doi.org/10.1016/i.conbuildmat.2020.118873

[5] S. Yoon, J. Moon, S. Bae, X. Duan, E.P. Giannelis, P.M. Monteiro, Chloride adsorption by calcined layered double hydroxides in hardened Portland cement paste. Mater Chem Phys (2014) 145: 376386. https://doi.org/10.1016/i.matchemphys.2014.02.026

[6] T.M. Rossi, J.C. Campos, M.M.V.M. Souza, An evaluation of calcined hydrocalumite as carbon dioxide adsorbent using thermogravimetric analysis. Appl Clay Sci (2019) 182: 105252. https://doi.org/10.1016/j.clay.2019.105252

[7] E. Pérez-Barrado, P. Salagre, L.F. Marsal, M. Aguiló, Y. Cesteros, F. Díaz, J. Pallarès, F. Cucinotta, L. Marchese, M.C. Pujol, Ultrasoundassisted reconstruction and delamination studies on CaAl layered double hydroxides. Appl Clay Sci (2015) 118: 116-123. https://doi.org/10.1016/j.clay.2015.08.043

[8] Y. Wu, P. Duan, C. Yan, Role of layered double hydroxides in setting, hydration degree, microstructure and compressive strength of cement paste. Appl Clay Sci (2018) 158: 123-131. https://doi.org/10.1016/j.clay.2018.03.024

[9] X. Ke, S.A. Bernal, J.L. Provis, Controlling the reaction kinetics of sodium carbonate-activated slag cements using calcined layered double hydroxides. Cem Concr Res (2016) 81: 24-37. https://doi.org/10.1016/j.cemconres.2015.11.012

[10] Taylor H.F.W. Cement chemistry. 2o ed, London: Thomas Telford, 1997. https://doi.org/10.1680/cc.25929

[11] B. Lothenbach, L. Pelletier-Chaignat, F. Winnefeld, Stability in the system $\mathrm{CaO}-\mathrm{Al}_{2} \mathrm{O}_{3}-\mathrm{H}_{2} \mathrm{O}$. Cem Concr Res (2012) 42: 1621-1634 https://doi.org/10.1016/j.cemconres.2012.09.002

[12] J.M. Rivas-Mercury, P. Pena, A.H. Aza, X. Turrillas, Dehydration of $\mathrm{Ca}_{3} \mathrm{Al}_{2}\left(\mathrm{SiO}_{4}\right)_{y}(\mathrm{OH})_{4(3-\mathrm{y})} \quad(0<\mathrm{y}<0.176) \quad$ studied by neutron thermodiffractometry. J Eur Ceram Soc (2008) 28: 1737-1748. https://doi.org/10.1016/j.jeurceramsoc.2007.12.038

[13] L. Zhang, Y. Ji, J. Li, F. Gao, G. Huang, Effect of retarders on the early hydration and mechanical properties of reactivated cementitious material. Constr Build Mater (2019) 212: 192-201. https://doi.org/10.1016/j.conbuildmat.2019.03.323

[14] B. Paul, W. Chang, Mayenite-to-hydrocalumite transformation for the removal of chloride from salinized groundwater and the recycling potential of spent hydrocalumite for chromate removal. Desalination (2020) 474: 114186. https://doi.org/10.1016/j.desal.2019.114186

[15] T.R.S. Nobre, A.P. Kirchheim, A. Takimi, Síntese da katoita (C3AH6) por ativação mecanoquímica do $\mathrm{Ca}(\mathrm{OH}) 2$ e $\mathrm{Al}(\mathrm{OH}) 3$. In: Blucher Proceedings IX Encontro Científico de Física Aplicada Blucher, 2018. https://doi.org/10.5151/ecfa2018-05

[16] J. Qu, L. Zhong, Z. Li, M. Chen, Q. Zhang, X. Liu, Effect of anion addition on the syntheses of Ca-Al layered double hydroxide via a two-step mechanochemical process. Appl Clay Sci (2016) 124-125: 267-270. https://doi.org/10.1016/j.clay.2016.02.026

[17] L.G. Baquerizo, T. Matschei, K.L. Scrivener, M. Saeidpour, L. Wadsö, Hydration states of AFm cement phases. Cem Concr Res (2015) 73: 143-157. https://doi.org/10.1016/j.cemconres.2015.02.011

[18] W. Kim, F. Saito, Mechanochemical synthesis of tricalcium aluminum hydrate from calcium hydroxide-boehmite mixtures by room temperature grinding. Shigen-to-Sozai (1998) 114: 549-552. https://doi.org/10.2473/shigentosozai.114.549

[19] S. Miyata, Anion-exchange properties of hydrotalcite-like compounds. Clays Clay Miner (1983) 31(4): 305-311. https://doi.org/10.1346/CCMN.1983.0310409

[20] M.H. Maciel, Influência do ligante pré-hidratado nas propriedades de suspensões de cimento Portland. Dissertation. Universidade de São Paulo, 2017. 
[21] C.A. Geiger, E. Dachs, A. Benisek, Thermodynamic behavior and properties of katoite (hydrogrossular): A calorimetric study. Amer Miner (2012) 97: 1252-1255. https://doi.org/10.2138/am.2012.4106

[22] A. Eisinas, T. Dambrauskas, K. Baltakys, K. Ruginyte, The peculiarities of mayenite formation from synthetic katoite and calcium monocarboaluminate samples in temperature range $25-1150{ }^{\circ} \mathrm{C}$. J Therm Anal Calorim (2019) 138: 2275-2282. https://doi.org/10.1007/s10973-019-08482-4

[23] M.U. Okoronkwo, F.P. Glasser, Compatibility of hydrogarnet, $\mathrm{Ca}_{3} \mathrm{Al}_{2}\left(\mathrm{SiO}_{4}\right)_{x}(\mathrm{OH})_{4(3-x)}$, with sulfate and carbonate-bearing cement phases: $5-85^{\circ} \mathrm{C}$. Cem Concr Res (2016) 83: 86-96. https://doi.org/10.1016/j.cemconres.2016.01.013

[24] A.J. Majumdar, R. Roy, The System CaO-Al2O3-H2O. J Am Ceram Soc (1956) 39(12): 434-442 https://doi.org/10.1111/j.1151-2916.1956.tb15618.x

[25] L. Schröpfer, H. Bartl, Oriented decomposition and reconstruction of hydrogarnet, $\mathrm{Ca}_{3} \mathrm{Al}_{2}(\mathrm{OH})_{12}$. Eur J Mineral (1993) 5: 1133-1144. https://doi.org/10.1127/ejm/5/6/1133

[26] F. Šoukal, J. Koplík, P. Ptáček, T. Opravil, J. Havlica, M.T. Palou, L. Kalina, The influence of $\mathrm{pH}$ buffers on hydration of hydraulic phases in system $\mathrm{CaO}_{2} \mathrm{Al}_{2} \mathrm{O}_{3}$. J Therm Anal Calorim (2016) 124: 629-638. https://doi.org/10.1007/s10973-015-5190-z

[27] R.N. Edmonds, A.J. Majumdar, The hydration of $12 \mathrm{CaO} .7 \mathrm{~A} 12 \mathrm{O} 3$ at different temperatures. Cem Concr Res (1988) 18: 473-478. https://doi.org/10.1016/0008-8846(88)90082-8

[28] K. Nakagawa, I. Terashima, K. Asaga, M. Daimon, A study of hydration of amorphous calcium aluminate by selective dissolution analysis. Cem Concr Res (1990) 20: 655-661. https://doi.org/10.1016/0008-8846(90)90108-A

[29] D. Damidot, S.A. Stronach, A. Kindness, M. Atkins, F.P. Glasser. Thermodynamic investigation of the CaO-Al2O3-CaCO3-H2O closed system at $25^{\circ} \mathrm{C}$ and the influence of Na2O. Cem Concr Res (1994) 24(3): 563-572. https://doi.org/10.1016/0008-8846(94)90145-7

[30] H.P. Klug, L.E. Alexander, X-Ray diffraction procedures: for polycrystalline and amorphous materials. 2o ed, 1974.

[31] J.V. Alemán J.V., A.V. Chadwick, J. He, M. Hess, K. Horie, R.G. Jones, P. Kratochvíl, I. Meisel, I. Mita, G. Moad, S. Penczek, R.F.T. Stepto, Definitions of terms relating to the structure and processing of sols, gels, networks, and inorganic-organic hybrid materials (IUPAC Recommendations 2007). Pure Appl Chem (2007) 79(10): 1801-1829. https://doi.org/10.1351/pac200779101801

[32] B.L. Caetano, V. Briois, S.H. Pulcinelli, F. Meneau, C.V. Santilli, Revisiting the $\mathrm{ZnO}$ Q-dot formation toward an integrated growth model: from coupled time resolved UV-vis/SAXS/XAS data to multivariate analysis. J Phys Chem C (2017) 121: 886-895. https://doi.org/10.1021/acs.jpcc.6b10062

[33] N. Roussel, A. Lemaître, R.J. Flatt, P. Coussot, Steady state flow of cement suspensions: A micromechanical state of the art. Cem Concr $\operatorname{Res}$ (2010) 40(1): 77-84. https://doi.org/10.1016/j.cemconres.2009.08.026

[34] Z. Toutou, N. Roussel, Multi scale experimental study of concrete rheology: From water scale to gravel scale. Mater Struct (2006) 39: 189-199. https://doi.org/10.1617/s11527-005-9047-y

[35] J. Claramunt, H. Ventura, M. Ardanuy, Rheology of CAC-based cement pastes and the relationship to penetrability through nonwoven fabric reinforcements. Cem Concr Compos (2018) 94: 8593. https://doi.org/10.1016/i.cemconcomp.2018.08.014

[36] J. Wang, M. Mu, Y. Liu, Recycled cement. Constr Build Mater (2018) 190: 1124-1132. https://doi.org/10.1016/j.conbuildmat.2018.09.181

[37] N. Roussel, Understanding the rheology of concrete. Woodhead Publishing, 2012. https://doi.org/10.1533/9780857095282

[38] M.A. Schultz, L.J. Struble, Use of oscillatory shear to study flow behavior of fresh cement paste. Cem Concr Res (1993) 23(2): 273282. https://doi.org/10.1016/0008-8846(93)90092-N

[39] R.C.O. Romano, M.H. Maciel, R.G. Pileggi, M.A. Cincotto, Monitoring of hardening of Portland cement suspensions by Vicat test, oscillatory rheometry, and isothermal calorimetry. Appl Rheol (2017) 27: 36006.

[40] M. Fourmentin, P. Faure, S. Gauffinet, U. Peter, D. Lesueur, D. Daviller, G. Ovarlez, P. Coussot, Porous structure and mechanical strength of cement-lime pastes during setting. Cem Concr Res (2015) 77: 1-8. https://doi.org/10.1016/i.cemconres.2015.06.009

[41] Y. Chen, R. Yu, X. Wang, J. Chen, Z. Shui. Evaluation and optimization of Ultra-High Performance Concrete (UHPC) subjected to harsh ocean environment: Towards an application of Layered Double Hydroxides (LDHs). Constr Build Mater (2018) 177: 51-62. https://doi.org/10.1016/j.conbuildmat.2018.03.210
[42] N. Roussel, Rheological requirements for printable concretes. Cem Concr Res (2018) 112: 76-85. https://doi.org/10.1016/i.cemconres.2018.04.005 